\title{
Sensitivity analysis of Takagi-Sugeno-Kang rainfall-runoff fuzzy models
}

\author{
A. P. Jacquin ${ }^{1}$ and A. Y. Shamseldin ${ }^{2}$ \\ ${ }^{1}$ Departamento de Obras Civiles, Universidad Técnica Federico Santa María, Casilla 110-V, Valparaíso, Chile \\ ${ }^{2}$ Department of Civil and Environmental Engineering, The University of Auckland, Private Bag 92019, \\ Auckland, New Zealand
}

Received: 3 June 2008 - Published in Hydrol. Earth Syst. Sci. Discuss.: 18 July 2008

Revised: 12 December 2008 - Accepted: 12 December 2008 - Published: 23 January 2009

\begin{abstract}
This paper is concerned with the sensitivity analysis of the model parameters of the Takagi-Sugeno-Kang fuzzy rainfall-runoff models previously developed by the authors. These models are classified in two types of fuzzy models, where the first type is intended to account for the effect of changes in catchment wetness and the second type incorporates seasonality as a source of non-linearity. The sensitivity analysis is performed using two global sensitivity analysis methods, namely Regional Sensitivity Analysis and Sobol's variance decomposition. The data of six catchments from different geographical locations and sizes are used in the sensitivity analysis. The sensitivity of the model parameters is analysed in terms of several measures of goodness of fit, assessing the model performance from different points of view. These measures include the Nash-Sutcliffe criteria, volumetric errors and peak errors. The results show that the sensitivity of the model parameters depends on both the catchment type and the measure used to assess the model performance.
\end{abstract}

\section{Introduction}

There are several issues arising during the calibration of the parameters of a rainfall-runoff model, including the selection of calibration and verification data, the quality and information contents of these data, the selection of an optimisation algorithm, the choice of suitable criteria for evaluating the model performance, and problems with the parametric structure of the model. This paper is mainly concerned with the problems found in the parametric structure of the model, which can be broadly classified as those associated with pa-

Correspondence to: A. P. Jacquin

(alejacquin@yahoo.com) rameter insensitivity and those arising from parameter interactions. The sensitivity analysis of a rainfall-runoff model permits the detection of these parameter insensitivities and interactions, determining the relative importance of the different model parameters in the performance of the model. If the result of the sensitivity analysis indicates that some model parameters are unimportant in determining the model performance, then it is possible to fix them to some chosen appropriate values, thus reducing the dimensionality of the search space for subsequent model calibration (Saltelli et al., 2004). Most typically, sensitivity analysis is performed by studying the characteristics of the model response surface, which is basically the multidimensional surface defined by the model parameters and the objective function values (e.g. Sorooshian and Gupta, 1995; Xiong and O'Connor, 2000). Nevertheless, the sensitivity of the model predictions to other input factors, such as land use (Nandakumar and Mein, 1997; Hundecha and Bárdossy, 2004) or initial soil moisture conditions (e.g. Zehe and Blöschl, 2004; Zehe et al., 2005), is also possible.

Parameter insensitivity refers to the case where the objective function values are not largely affected by variations in the values of one or more parameters. However, this does not mean that the time series of discharge estimations does not vary with changes in these parameters (Wagener et al., 2002 ) or that the parameter is redundant in the model structure (O'Connor, 2005). Firstly, it is possible that even though the model output is affected by the values taken by some parameters, the chosen objective function gives little emphasis to the response modes associated with them. In this case, the sensitivity of the model to these apparently insensitive parameters can be observed by analysing the variations in measures of model performance other than the chosen objective function (Wagener et al., 2002). Secondly, it is possible that

Published by Copernicus Publications on behalf of the European Geosciences Union. 
the model output seems to be insensitive to the values of one or more of the model parameters, because the model components related to them are not activated by the calibration data (Sorooshian and Gupta, 1995; Beven, 2001). In order to prevent this situation, it is necessary to ensure that the data chosen for model calibration is informative/representative, in the sense that it encompasses a wide range of conditions in which the model is expected to operate.

In addition to this, the model structure itself may be such that the response surface suffers from parameter interactions at a local and/or a global scale. Parameter interactions at a local scale occur when simultaneous changes in two or more parameters seem to compensate with respect to the value of the objective function, creating elongated valleys along which the parameter vector may move without evident variations in the height of the model response surface. Another problem which often affects the model response surface of rainfall-runoff models is that of multiple local optima, which can be seen as a kind of parameter interaction at a global scale. From the point of view of the identification of insensitive model parameters, the importance of parameter interactions is that a parameter which does not individually affect the model performance can still have strong influence through interactions with other parameters (Saltelli et al., 2004).

The purpose of this paper is to study the sensitivity of the parameters of the Takagi-Sugeno-Kang (Takagi and Sugeno, 1985; Sugeno and Kang, 1988) rainfall-runoff fuzzy models previously developed by Jacquin and Shamseldin (2006). Takagi-Sugeno-Kang fuzzy models involve complex nonlinear relationships between the model output and the model parameters; thus, it is expected that the model response surface is affected both by interactions at a local scale and multiple optima. In this case, the application of traditional local sensitivity analysis methods (i.e. the examination of changes in the model output due to changes in the parameters values in the vicinity of the some nominal/optimal parameter set) is not a suitable alternative for determining whether or not a particular model parameter is important. Accordingly, in this study the sensitivity of the model parameters is analysed using global sensitivity analysis methods, namely Regional Sensitivity Analysis (Spear and Hornberger, 1980; Hornberger and Spear, 1981) and Sobol's variance decomposition (Sobol, 1993). In the authors' present knowledge, there are currently no studies dealing with the sensitivity analysis of fuzzy-based rainfall-runoff models using such methods.

\section{Sensitivity analysis methods}

\subsection{Local versus global methods}

Local sensitivity analysis (LSA) methods measure the sensitivity of a quantity $Y$ under examination to small variations in the model parameters, with respect to some chosen nomi- nal values (Beven, 2001). Classical LSA methods are based on the calculation of the derivatives

$S_{p}=\frac{\partial Y}{\partial \theta_{p}}$,

where $Y$ represents the output quantity under examination (e.g. some measure of model performance) and $\theta_{p}$ represents a model parameter. These derivatives are usually approximated by finite differences, i.e. by evaluation of the change $\Delta Y$ that results from a small change $\Delta \theta_{p}$ in the parameter $\theta_{p}$, while the remaining components of the parameter vector remain constant at their nominal values. Applications of LSA methods in hydrological modelling include the work of Mein and Brown (1978), Gupta and Sorooshian (1985) and Castaings et al. (2005), among others.

There are two main drawbacks of LSA methods that make them inappropriate for the case of model structures affected by parameter interactions, as frequently noted in the literature (Saltelli et al., 2004; Fieberg and Jenkings, 2005; Pappenberger et al., 2008). In the first place, the local estimates of parameter sensitivity obtained with these methods do not provide any information about the effect of variations of the models parameters across their feasible ranges. In addition to this, LSA methods are unable to detect the effect of parameter interactions, because only one parameter is varied at a time.

Global sensitivity analysis (GSA) methods attempt to answer the question of whether or not a particular parameter $\theta_{p}$ is, overall, an important factor in determining the value of the quantity $Y$. For this purpose, GSA methods estimate to what extent the value of $Y$ is affected by variations in the value of each parameter $\theta_{p}$ across its feasible range. Furthermore, some of these methods also analyse the effect of simultaneous changes in the values of the remaining parameters, thus accounting for parameter interactions in the model structure. Several of GSA methods are described in the literature, including regression analysis (see e.g. Saltelli et al., 2004), the method of Morris (Morris, 1991), Regional Sensitivity Analysis (Spear and Hornberger, 1980; Hornberger and Spear, 1981) and Sobol's variance decomposition (Sobol, 1993).

\subsection{GSA methods applied in this study}

\subsubsection{Regional sensitivity analysis}

Regional Sensitivity Analysis (RSA) is a GSA method widely used in hydrological modelling (e.g. McIntyre et al., 2003; Mertens et al., 2005; Pappenberger et al., 2008; Tang et al., 2007). Monte Carlo sampling is used for obtaining a large sample of parameter sets and the corresponding values of the output quantity $Y$. The parameter sets in the sample are then classified as either behavioural or non-behavioural, according to some a priori fixed criterion concerning the value of $Y$. Thus, the sample of parameter sets is split into a behavioural $(\mathrm{S})$ and a non-behavioural sub-sample $\left(\mathrm{S}^{*}\right)$. For 
each model parameter $\theta_{p}$, the empirical cumulative probability distribution from each sub-sample is calculated. In the case of a sensitive parameter, the probability distribution from the behavioural sub-sample greatly differs from that of the non-behavioural sub-sample. In contrast, these probability distributions are essentially the same if the performance of the model is relatively insensitive to variations of the parameter $\theta_{p}$ alone. The cumulative probability distribution from the behavioural set $\left(F_{S}\left(\theta_{p}\right)\right)$ and the non-behavioural set $\left(F_{S *}\left(\theta_{p}\right)\right)$ are compared using a Kolmogorov-Smirnov test.

The RSA method is mainly concerned with the effect of unilateral variations of the parameters, as pointed out by Saltelli et al. (2004) and Tang et al. (2007). The method is based on simultaneous variations of all the parameters, but it ultimately relies on the comparison of univariate probability distributions $F_{S}\left(\theta_{p}\right)$ and $F_{S *}\left(\theta_{p}\right)$. Even though this approach can implicitly account for some kinds of interaction structures, this is not the general situation and there are several types of interaction effects that are obscured by a mere comparison of univariate probability distributions (see e.g. Saltelli et al., 2008). Accordingly, at least in principle, the method is unable to deal with parameter interactions. In fact, Spear and Hornberger (1980) clarify that the equality of the distributions $F_{S}\left(\theta_{p}\right)$ and $F_{S *}\left(\theta_{p}\right)$ is a necessary but not a sufficient condition for the insensitivity of the parameter $\theta_{p}$. That is, great differences between $F_{S}\left(\theta_{p}\right)$ and $F_{S *}\left(\theta_{p}\right)$ always prove the sensitivity of the parameter $\theta_{p}$. However, the similarity of $F_{S}\left(\theta_{p}\right)$ and $F_{S *}\left(\theta_{p}\right)$ does not necessarily imply that the parameter $\theta_{p}$ is unimportant, because it could still have relevance through interactions whose effects are not detected by the method. This limitation can be partially overcome by analysing bivariate covariance structures of the parameters in the behavioural sub-sample, either through visual analysis of 2-D plots of or through correlation analysis. However, this approach only provides information about bivariate interactions, while higher order interaction effects are not revealed (Saltelli et al., 2008).

In this study, the RSA method is applied in the manner proposed by Wagener et al. (2001). A Monte Carlo sample of parameter sets is produced and sorted according to the value of the output quantity $Y$ under analysis. The sorted sample is subsequently split into 10 sub-samples of equal size and, for every model parameter, the cumulative probability distribution within each sub-sample is plotted. Visual comparison of the cumulative probability distributions associated with the different sub-samples allows the detection of sensitive parameters, which are necessarily associated with visible discrepancies between these probability distributions. If these discrepancies are not observed, it is both possible that the parameter is overall insensitive or that it only affects the model performance through interactions that are not detected by the RSA method.

\subsubsection{Sobol's variance decomposition}

Sobol's variance decomposition (SVD) is a GSA method that is receiving increasing attention from hydrologists (e.g. Francos et al., 2003; Kanso et al., 2005; Wang et al., 2006; Ratto et al., 2007; Tang et al., 2007). SVD has the advantage over RSA of being able to deal with all kinds of parameter interactions in the model structure. Even though a more detailed description of SVD can be found in the dedicated literature (e.g. Chan et al., 2000; Saltelli et al., 2000), its basic features are given in what follows.

The SVD method uses the model output variance $V[Y]$ as a measure of the variability of the quantity $Y$, which may depend, in principle, on the values assigned to all the individual model parameters $\theta_{p}$. The output variance $V[Y]$ is calculated by exploration of the whole feasible space of the parameter set. If the model parameters are not correlated, the output variance $V[Y]$ can be decomposed in the following sum (Sobol, 1993)

$V[Y]=\sum_{p} V_{p}+\sum_{p} \sum_{q>p} V_{p q}+\ldots+V_{1,2, \ldots, P}$,

where term $V_{p}$ represents the portion of the variance of $Y$ that is due to changes in the parameter $\theta_{p}$ alone. Higher order terms indicate the portion of the total variance exclusively due to interactions between two or more parameters; for example, the term $V_{p q}$ quantifies the joint contribution of $\theta_{p}$ and $\theta_{q}$ to the variance of $Y$, minus $V_{p}$ and $V_{q}$.

There are two sensitivity indices provided by the SVD method that will be used in this study, namely the first-order effects and the total effects. The first-order effect of $\theta_{p}$ on $Y$, defined as (Sobol, 1993)

$S_{p}=\frac{V_{p}}{V[Y]}$,

measures to what extent the parameter $\theta_{p}$ individually affects the output quantity $Y$, independently of other model parameters. As mentioned by Saltelli et al. (2004), this means that evaluating first-order effects provides similar information to that of the RSA method. In reference to Eq. (2), the firstorder effect $S_{p}$ represents the fraction of the output variance $V[Y]$ that would be removed if the value of the parameter $\theta_{p}$ could be fixed (see e.g. Saltelli et al., 2004). The total effect $S_{T p}$ of the parameter $\theta_{p}$ is given by (Homma and Saltelli, 1996)

$S_{T p}=\frac{V_{p}}{V[Y]}+\frac{\sum_{q \neq p} V_{p q}}{V[Y]}+\frac{\sum_{q \neq p} \sum_{r>q} V_{p q r}}{V[Y]}+\ldots$,

which is esentially the sum of the first-order effect and all the higher order terms in Eq. (2) that involve $\theta_{p}$. Therefore, the total effect $S_{T p}$ indicates the overall importance of the parameter $\theta_{p}$ in the variability of $Y$, including both its firstorder effect and interactions with other parameters. Mathematically, the total effect $S_{T p}$ measures the fraction of the 
output variance $V[Y]$ that would remain if the value of $\theta_{p}$ was unknown, but the true values of the remaining parameters could be fixed (see e.g. Saltelli et al., 2004). In the case of non-correlated parameters, the total effect $S_{T p}$ is greater than or equal to the first-order effect $S_{p}$.

The analysis of first-order effects and total effects allows a straightforward diagnose of parameter sensitivities (Saltelli et al., 2004). If the total effect of a parameter is small, it can be concluded that the parameter is not important in determining the value of $Y$; by contrast, large total effects are necessarily associated with influential parameters. In addition to this, the difference between the total effect and the first-order effect of a parameter indicates to what extent the parameter is involved in interactions with others parameters. Finally, a large first-order effect proves that a parameter is influential on its own, independently of interactions with other parameters, while a small first-order effect found together with a large total effect shows that the parameter affects the output $Y$ mainly through interactions with other parameters.

Variance decompositions similar to that of Eq. (2) can be written by grouping the parameters into subsets (see e.g. Saltelli et al., 2004). In that case, the first-order effect of a group of parameters indicates to what extent the parameters in the group affect the output quantity $Y$, excluding the effect of interactions with parameters in other groups. The total effect of a group of parameters includes both the firstorder effect of the group and the interactions with parameters outside the group. Thus, the total effect of a group of parameters is a measure of the overall importance of the group of parameters in the variability of $Y$.

Although Monte Carlo methods can be used for the purpose of exploring the feasible space of the parameter set when calculating the variance terms in Eq. (2), these may be very computationally demanding (Saltelli et al., 2004; Tang et al., 2007). In the case of non-correlated parameters, the FAST method (Cukier et al., 1973; Cukier et al., 1978) is a sampling strategy for the calculation of first-order effects at a lower computational cost. Saltelli et al. (1999) further developed this latter method into the Extended FAST method, which allows the simultaneous calculation of first-order and total effects.

\section{Models description}

\subsection{Takagi-Sugeno-Kang fuzzy models}

The fundamental elements of fuzzy sets theory were first proposed more than four decades ago (Zadeh, 1965), but applications of related modelling tools in hydrology are relatively recent (see e.g. Demicco and Klir, 2004). Applications of fuzzy methods in the hydrological context include modelling groundwater flow phenomena (Bárdossy and Disse, 1993; Bárdossy et al., 1995; Dou et al., 1999), and the interdependence between global circulation and precipita- tion (Özelkan et al., 1998; Pongracz et al., 2001; Zehe et al., 2006), for example. In the narrower context of river flow forecasting, fuzzy methods have been used for parameter estimation (Seibert, 1999; Yu and Yang, 2000), uncertainty analysis (Özelkan and Duckstein, 2001; Bárdossy et al., 2006; Jacquin and Shamseldin, 2007) and the development of rainfall-runoff models (Hundecha and Bárdossy, 2001; Vernieuwe et al., 2005), among other applications.

Fuzzy inference systems, or fuzzy models, are non-linear models that intend to describe the input-output relationship of a real system using a set of fuzzy IF-THEN rules and the inference mechanisms of fuzzy logic. In the case of Takagi-Sugeno-Kang (TSK) fuzzy inference systems, each fuzzy rule represents a local model of the real system under consideration (Takagi and Sugeno, 1985). The $m_{t h}$ rule of a TSK system with input vector $\boldsymbol{X}=\left(\boldsymbol{X}_{1}, \boldsymbol{X}_{2}, \ldots, \boldsymbol{X}_{K}\right)$ and output $Y$ has the general form

IF $\left(\boldsymbol{X}_{1}\right.$ is $\left.A_{1, m}\right)$ AND $\left(\boldsymbol{X}_{2}\right.$ is $\left.A_{2, m}\right)$ AND...AND

$\left(\boldsymbol{X}_{K}\right.$ is $\left.A_{K, m}\right)$ THEN $Y=f_{m}(\boldsymbol{X})$

where the linguistic terms $A_{k, m}$ in the rule antecedents (i.e. the IF parts of the rules) represent fuzzy sets (Zadeh, 1965) with membership functions, $\mu_{k, m}\left(x_{k}\right)$, which are used to partition the domains of the input variables into overlapping regions. The functions $f_{m}$ in the rule consequents (i.e. the THEN parts of the rules) are usually first-order polynomials having the form

$f_{m}\left(\boldsymbol{X}_{1}, \boldsymbol{X}_{2}, \ldots, \boldsymbol{X}_{K}\right)=b_{0, m}+b_{1, m} \boldsymbol{X}_{1}+b_{2, m} \boldsymbol{X}_{2}, \ldots, b_{K, m} \boldsymbol{X}_{K}$.

For a given input $\boldsymbol{X}=x=\left(x_{1}, x_{2}, \ldots, x_{K}\right)$, the degree of fulfilment (DOF) of each rule evaluates the compatibility of the input $\boldsymbol{X}=x=\left(x_{1}, x_{2}, \ldots, x_{K}\right)$ with the rule antecedent and ultimately determines the contribution of the rule's response $y=f_{m}\left(x_{1}, x_{2}, \ldots, x_{K}\right)$ to the overall model's output. In the case of Gaussian type membership functions, whose analytical expression is given by

$\mu_{k, m}\left(x_{k}\right)=\exp \left[-\frac{\left(x_{k}-c_{k, m}\right)^{2}}{2 \sigma_{k, m}^{2}}\right]$,

each membership function has two parameters, namely the centre $c_{k, m}$ and the spread $\sigma_{k, m}$. The degree of firing is frequently evaluated using the product operator, in which case it can be expressed as

$\operatorname{DOF}_{m}(x)=\mu_{A_{1, m}}\left(x_{1}\right) \cdot \mu_{A_{2, m}}\left(x_{2}\right) \cdot \ldots \cdot \mu_{A_{K, m}}\left(x_{K}\right)$.

Finally, the overall output of a normalised first-order TSK fuzzy model with $M$ rules is calculated according to

$y=$
$\frac{\sum_{m=1}^{M} \mathrm{DOF}_{m}\left(x_{1}, x_{2}, \ldots, x_{K}\right) \cdot\left[b_{0, m}+b_{1, m} x_{1}+b_{2, m} x_{2}+\ldots+b_{K, m} x_{K}\right]}{\sum_{m=1}^{M} \operatorname{DOF}_{m}\left(x_{1}, x_{2}, \ldots, x_{K}\right)}$. 


\subsection{Rainfall-runoff fuzzy models under investigation}

The rainfall-runoff models under investigation, previously proposed by Jacquin and Shamseldin (2006), correspond to TSK type fuzzy inference systems having the discharge in the catchment outlet as output variable. A brief description of these models is given in what follows, but further details on their interpretation and similarities with existing rainfall-runoff models can be found in the work by Jacquin and Shamseldin (2006).

The models can be classified in two types, each intended to account for different kinds of dominant non-linear effects in the rainfall-runoff relationship. Fuzzy models type 1 are intended to incorporate the effect of changes in the prevailing soil moisture content, while fuzzy models type 2 address the phenomenon of seasonality. Each fuzzy model type consists of five model structures of increasing complexity, where the most complex fuzzy models TSK1.5 and TSK2.5 include all the model components found in the remaining fuzzy models of the respective type. The rules of the fuzzy models are given by

TSKmtype.1 : IF ( $V_{\text {mtype }}$ is $\left.A_{m}\right){ }^{`}$ THEN $Q^{n}=b_{0, m}$,

TSKmtype.2 : IF ( $V_{\text {mtype }}$ is $\left.A_{m}\right)$ THEN $Q^{n}=b_{1, m} \mathrm{RI}^{n}$,

TSKmtype. 3 : IF ( $V_{\text {mtype }}$ is $\left.A_{m}\right)$ THEN

$$
Q^{n}=b_{0, m}+b_{1, m} \mathrm{RI}^{n}
$$

TSKmtype.4 : IF ( $V_{\text {mtype }}$ is $\left.A_{m}\right)$ THEN

$$
Q^{n}=b_{2, m} \cdot \sum_{j=1}^{L} h_{j, m} P_{i-j+1}^{n},
$$

TSKmtype.5 : IF ( $V_{\text {mtype }}$ is $\left.A_{m}\right)$ THEN

$$
Q^{n}=b_{0, m}+b_{2, m} \cdot \sum_{j=1}^{L} h_{j, m} P_{i-j+1}^{n},
$$

where mtype represents the model type, i.e. type 1 or 2 . In all cases, the output variable in the rule consequents is given by the normalised discharge $Q^{n}$, calculated as the quotient between the discharge at the catchment outlet $Q$ and the maximum discharge $Q_{\max }$ observed during the calibration period.

The choice of antecedent input variable $V_{\text {mtype }}$ depends on the fuzzy model type under consideration. In the case of fuzzy models type 1, this corresponds to a normalised rainfall index $\mathrm{RI}^{n}$, intended to give an indication of the prevailing soil moisture conditions in the catchment. Accordingly, the rule consequents of fuzzy models type 1 can be seen as local models of the rainfall-runoff relationship, valid for some fuzzily defined range of soil moisture content. At each time step $i$, the output of an auxiliary Simple Linear Model (SLM) of Nash and Foley (1982) is used to calculate the current rainfall index value $\mathrm{RI}_{i}$ from to the convolution summation

$\mathrm{RI}_{i}=G^{a} \cdot \sum_{j=1}^{L} P_{i-j+1} \cdot h_{j}^{a}$ where $P_{j}$ is the rainfall measurement at time step $j, L$ is the memory length of the catchment, $G^{a}$ is the gain factor of the auxiliary SLM and $h_{j}^{a}$ is the $j_{t h}$ ordinate of the discrete pulse response function of the auxiliary SLM. The rainfall index $\mathrm{RI}_{i}$ is subsequently divided by its maximum value $\mathrm{RI}_{\max }$ found during the calibration period, in order to obtain the normalised rainfall index $\mathrm{RI}_{i}^{n}$ (i.e. $\mathrm{RI}^{n}=\mathrm{RI} / \mathrm{RI}_{\max }$ ). With the aim of keeping the number of parameters to a minimum, the discrete pulse response ordinates $h_{j}^{a}$ of the auxiliary SLM are obtained in parametric form using the gamma distribution model of Nash (1957). Fuzzy models type 2 use the time of the year $t$ (in days) as input information to the rule antecedents. This is accomplished by calculating a normalised time of the year $t^{n}$, given by

$t^{n}=t / 365$

which is ultimately used as antecedent input variable. Each rule consequent of a type 2 fuzzy model can be seen as a model of the rainfall-runoff relationship that is associated with a particular season (fuzzily defined period) of the year.

Gaussian type membership functions, defined in Eq. (7), are chosen for modelling the antecedent fuzzy sets. However, in the case of fuzzy models type 1, the analytical expression of the leftmost (rule 1) and rightmost (rule $M$ ) membership function are modified in the following manner

$$
\begin{aligned}
& \mathrm{DOF}_{1}\left(\mathrm{RI}^{n}\right)=\mu_{1}\left(\mathrm{RI}^{n}\right)=\left\{\begin{array}{ll}
1, & \mathrm{RI}^{n}<c_{1} \\
\exp \left[-\frac{\left(R I^{n}-c_{1}\right)^{2}}{2 \sigma_{1}^{2}}\right], & \mathrm{RI}^{n} \geq c_{1}
\end{array},\right. \\
& \mathrm{DOF}_{M}\left(\mathrm{RI}^{n}\right)=\mu_{M}\left(\mathrm{RI}^{n}\right)=\left\{\begin{array}{ll}
\exp \left[-\frac{\left(\mathrm{RI}^{n}-c_{M}\right)^{2}}{2 \sigma_{M}^{2}}\right], & \mathrm{RI}^{n} \leq c_{M} \\
1, & \mathrm{RI}^{n}>c_{M}
\end{array},\right.
\end{aligned}
$$

while the membership function of the antecedent fuzzy sets of fuzzy models type 2 is given by

$\operatorname{DOF}_{m}\left(t^{n}\right)=\mu_{m}\left(t^{n}\right)=\exp \left[-\frac{\left(\min \left\{\left|t^{\mathrm{n}}-c_{\mathrm{m}}\right|, 1-\left|\mathrm{t}^{\mathrm{n}}-\mathrm{c}_{\mathrm{m}}\right|\right\}\right)^{2}}{2 \sigma_{m}^{2}}\right]$

in all cases. Details on the justification for Eq. (17) to (19) can be found in the study by Jacquin and Shamseldin (2006). In both types 1 and 2 fuzzy models, the description of each rule antecedent requires two parameters, namely the centres $c_{m}$ and the spreads $\sigma_{m}$ of the membership function, as shown in Table 1.

As seen in Eq. (10) to (14), the type of function $f_{m}$ found in the rule consequents depends on the model structure being considered. Accordingly, the parameters found in the rule consequents vary among the different model structures, as shown in Table 1. As discussed in the work by Jacquin and Shamseldin (2006), the fuzzy models TSK1.5 and TSK2.5 are the most complex among fuzzy models types 1 and 2 , respectively, because they include all the model components found in the remaining fuzzy models of the respective type. In particular, the rule consequents of the fuzzy models TSK1.5 and TSK2.5, as seen in Eq. (14), are first-order 
Table 1. Parameters involved in the TSK rainfall-runoff fuzzy models proposed by Jacquin and Shamseldin (2006).

\begin{tabular}{lccccccc}
\hline Model & $c_{m}$ & $\sigma_{m}$ & $b_{0, m}$ & $b_{1, m}$ & $b_{2, m}$ & $n_{m}$ & $(n K)_{m}$ \\
\hline TSKX.1 & $\checkmark$ & $\checkmark$ & $\checkmark$ & & & & \\
TSKX.2 & $\checkmark$ & $\checkmark$ & & $\checkmark$ & & & \\
TSKX.3 & $\checkmark$ & $\checkmark$ & $\checkmark$ & $\checkmark$ & & & \\
TSKX.4 & $\checkmark$ & $\checkmark$ & & & $\checkmark$ & $\checkmark$ & $\checkmark$ \\
TSKX.5 & $\checkmark$ & $\checkmark$ & $\checkmark$ & & $\checkmark$ & $\checkmark$ & $\checkmark$
\end{tabular}

polynomials on the most recent normalized rainfall values $P_{j}^{n}$, which include a free term $b_{0, m}$ in addition to first-order terms. These fuzzy models allow a different pulse response function for each rule $m$, characterized by gamma distribution parameters $n_{m}$ and $(n K)_{m}$ that define the pulse response ordinates $h_{j, m}$.

The sensitivity of the parameters of fuzzy models TSK1.5 and TSK2.5 is studied, in order to establish whether the parameters associated with a particular model component (e.g. the free terms in the rule consequents) are not important in determining the model performance. As mentioned earlier in the introduction, this situation would indicate that these parameters can be excluded from the search of the behavioural regions of the parameter space in a model calibration problem, by assigning them convenient values within their feasible ranges (Saltelli et al., 2004). In the case of the fuzzy models described here, this could be equivalent to considering a simpler model structure (e.g. fuzzy model TSK1.3 instead of TSK1.5), by removing the unimportant model component. The analysis is performed on fuzzy models with three rules, i.e. the same number of rules used in the study by Jacquin and Shamseldin (2006).

\section{Methodology}

\subsection{Catchments and data}

The data sets used in this study were obtained from the catchment database available at the Department of Engineering Hydrology, National University of Ireland, Galway. These data consist of daily averaged values of precipitation and daily average discharge at the catchment's outlet. Table 2 shows the location of the catchments and the length of the data sets. The rainfall-runoff relationship of three of the test catchments, namely Sunkosi-1, Yanbian and Brosna, is affected by significant seasonal effects; in the case of the remaining catchments, intrinsic non-linearity due to changes in soil moisture contents has greater importance. The catchments did not have hydrologically significant artificial structures or human intervention at the time when the measurements were made.

As shown in Table 2, the available data are divided into a calibration and a verification period for split-record simulations. In general, the calibration and the verification data from a same catchment have similar statistics (see Jacquin and Shamseldin, 2006). However, the variability of the calibration data of Bird Creek and Wollombi Brook is more pronounced than that of the corresponding verification data. In particular, the standard deviations of the discharge calibration data of these latter catchments are much higher than in verification, even though the calibration and the verification discharge data have similar means. The data used for the split sampling tests are considered to be sufficiently long and have enough information contents, including a wide range of hydrological conditions.

\subsection{Measures of model performance}

The sensitivity of the parameters of the fuzzy models TSK 1.5 and TSK2.5 with respect to the model performance is analysed in terms of several measures of goodness of fit, assessing different aspects of the agreement between the observed and the simulated hydrograph. Each performance measure represents an output quantity $Y$, whose variability (with respect to the parameters of the model) is to be examined.

The first performance measure under examination is the $R^{2}$ efficiency criterion of Nash and Sutcliffe (1970), given by the following expression

$R^{2}=\frac{\mathrm{MSE}_{0}-\mathrm{MSE}}{\mathrm{MSE}_{0}}$,

where the initial mean squared error $\mathrm{MSE}_{0}$ corresponds to the mean of the squares of the differences between the observed discharges and the long term mean during the calibration period. The mean squared error MSE is calculated as the mean of the squares of the differences between the model estimates and the observed discharges. The model efficiency $R^{2}$ is a decreasing function of the MSE, achieving a maximum value of unity if the model discharge estimates perfectly fit the observed discharges.

Another measure of goodness of fit used in this study is the deviation of runoff volumes, or relative error of the volumetric fit (REVF), given by

$\mathrm{REVF}=1-\frac{\sum Q_{i} *}{\sum Q_{i}}$,

where $Q_{i} *$ and $Q_{i}$ represent the model estimated and the observed discharge, respectively, at time step $i$. Positive REVF values indicate underestimation of discharge volumes, while negative REVF values are obtained when volumes are being overestimated.

The last measure of model performance considered in this study is the average relative error to the peak (REP), given by

$\mathrm{REP}=\sum_{i=1}^{N_{p}} \frac{\left|Q p_{i}-Q p_{i} *\right|}{N_{p} Q p_{i}}$

where $N_{p}$ is the number of selected flow peaks, $Q p_{i}$ represents a peak in the observed hydrograph, and $Q p_{i} *$ is the 
Table 2. Location of the catchments and length of the data sets used in the experiments, including the definition of calibration and verification periods for split sampling tests.

\begin{tabular}{|c|c|c|c|c|c|c|}
\hline \multirow[t]{2}{*}{ Catchment } & \multirow[t]{2}{*}{ Country } & \multirow{2}{*}{$\begin{array}{l}\mathrm{N}^{o} \text { of years } \\
\text { in data set }\end{array}$} & \multicolumn{2}{|c|}{ Calibration period } & \multicolumn{2}{|c|}{ Verification period } \\
\hline & & & starting date & $\mathrm{N}^{o}$ of years & starting date & $\mathrm{N}^{o}$ of years \\
\hline Sunkosi-1 & Nepal & 8 & 1 Jan 1975 & 6 & 1 Jan 1981 & 2 \\
\hline Yanbian & Central China & 8 & 1 Jan 1978 & 6 & 1 Jan 1984 & 2 \\
\hline Shiquan-3 & Central China & 8 & 1 Jan 1973 & 6 & 1 Jan 1979 & 2 \\
\hline Brosna & Central Ireland & 10 & 1 Jan 1969 & 8 & 1 Jan 1977 & 2 \\
\hline Bird Creek & Oklahoma, USA & 8 & 1 Jan 1955 & 6 & 1 Jan 1961 & 2 \\
\hline Wollombi Brook & New Sout Wales, Australia & 5 & 1 Jan 1963 & 4 & 1 Jan 1967 & 1 \\
\hline
\end{tabular}

Table 3. Performance statistics of the fuzzy models TSK 1.5 and TSK2.5.

\begin{tabular}{llllllll}
\hline \multirow{2}{*}{ Catchment } & Parameter group & \multicolumn{3}{c}{ Calibration } & \multicolumn{3}{c}{ Verification } \\
\cline { 3 - 8 } & & $R^{2 *}$ & REVF & REP & $R^{2 *}$ & REVF & REP \\
\hline \multirow{2}{*}{ Sunkosi-1 } & TSK1.5 & 0.88 & 0.00 & 0.21 & 0.84 & 0.21 & 0.32 \\
& TSK2.5 & 0.93 & 0.00 & 0.15 & 0.91 & 0.17 & 0.23 \\
Yanbian & TSK1.5 & 0.79 & 0.00 & 0.29 & 0.75 & 0.02 & 0.33 \\
& TSK2.5 & 0.84 & -0.01 & 0.26 & 0.79 & 0.09 & 0.31 \\
Shiquan-3 & TSK1.5 & 0.88 & 0.00 & 0.44 & 0.77 & -0.31 & 0.50 \\
Brosna & TSK2.5 & 0.84 & -0.12 & 0.41 & 0.36 & -0.39 & 0.67 \\
\multirow{3}{*}{ Bird Creek } & TSK1.5 & 0.42 & 0.00 & 0.42 & 0.49 & 0.14 & 0.45 \\
& TSK2.5 & 0.79 & 0.00 & 0.26 & 0.87 & 0.08 & 0.26 \\
Wollombi Brook & TSK1.5 & 0.87 & -0.07 & 0.74 & 0.13 & -0.19 & 0.84 \\
& TSK2.5 & 0.70 & -0.32 & 0.88 & -0.61 & -0.88 & 0.89 \\
& TSK1.5 & 0.89 & -0.07 & 0.53 & 0.73 & -0.79 & 1.69 \\
& TSK2.5 & 0.83 & -0.12 & 0.53 & -0.26 & -0.50 & 0.63 \\
\hline
\end{tabular}

$* R^{2}$ values taken from the study by Jacquin and Shamseldin (2006).

model estimated discharge for the same time step as $Q p_{i}$. The REP would be equal to zero in the ideal case of a perfect estimation of all the selected flow peaks; increasing REP values indicate deterioration in the ability of the model to estimate the peak discharges. In this study, the discharge peaks retained for the calculation of the REP values are those exceeding the $90 \%$ of the calibration discharge data.

Table 3 shows the model performance statistics $R^{2}$, REVF and REP of the fuzzy models TSK1.5 and TSK2.5, as calibrated by Jacquin and Shamseldin (2006). The fuzzy model TSK2.5 outperforms the fuzzy model TSK1.5 in terms of efficiency values $R^{2}$, when applied in the catchments whose rainfall-runoff relationship has a seasonal nature (i.e. Sunkosi-1, Yanbian and Brosna); but, this situation is reversed in the remaining catchments (i.e. Shiquan-3, Bird Creek and Wollombi Brook). In the non-seasonal catch- ments, the model efficiencies of TSK2.5 during the verification periods are quite low and also much lower than those of the calibration periods, which is an indication of model overfitting. The REVF values seen in Table 3 also show that there is no evidence that the presence/absence of seasonality determines which fuzzy model provides a better estimation of runoff volumes. However, it can be observed that both TSK1.5 and TSK2.5 give reasonable estimations of discharge volumes in the case of the seasonal catchments, with low REVF values during calibration and verification; the REVF values obtained by the fuzzy models when applied in the non-seasonal catchments are higher, especially during verification. Similarly, the REP values of both fuzzy models tend to be higher in the case of the non-seasonal catchments, indicating that the estimations of discharge peaks provided by the fuzzy models are worse in these cases. 
Table 4. Feasible ranges of the parameters of the fuzzy models TSK1.5 and TSK2.5.

\begin{tabular}{|c|c|c|c|}
\hline $\begin{array}{l}\text { Para- } \\
\text { meter }\end{array}$ & $\begin{array}{l}\text { Lower } \\
\text { bound }\end{array}$ & $\begin{array}{l}\text { Upper } \\
\text { bound }\end{array}$ & Description \\
\hline$c_{m}$ & 0 & 1 & $\begin{array}{l}\text { Centers of the antecedent } \\
\text { fuzzy sets }\end{array}$ \\
\hline$\sigma_{m}$ & 0.02 & 0.25 & $\begin{array}{l}\text { Spreads of the antecedent } \\
\text { fuzzy sets }\end{array}$ \\
\hline$b_{0, m}$ & $\begin{array}{l}-1.315 \\
-0.162\end{array}$ & $\begin{array}{l}1.456^{*} \\
0.641^{* *}\end{array}$ & $\begin{array}{l}\text { Free terms in the } \\
\text { consequent polynomials }\end{array}$ \\
\hline$b_{2, m}$ & 0 & $P_{\max } / Q_{\max }$ & $\begin{array}{l}\text { Coefficients of } \\
\text { first-order terms } \\
\text { in the consequent } \\
\text { polynomials }\end{array}$ \\
\hline$n_{m}$ & 0.5 & 10 & $\begin{array}{l}\text { Gamma distribution } \\
\text { parameters describing } \\
\text { the pulse responses } \\
\text { of the rule consequents }\end{array}$ \\
\hline$(n K)_{m}$ & 0.5 & 30 & $\begin{array}{l}\text { Gamma distribution } \\
\text { parameters describing } \\
\text { the pulse responses } \\
\text { of the rule consequents }\end{array}$ \\
\hline
\end{tabular}

* Bounds applicable to TSK1.5. ** Bounds applicable to TSK2.5.

\subsection{Computational experiments}

\subsubsection{Application of the RSA method}

A random sample of 40000 parameter sets is generated, both for the fuzzy model TSK1.5 and for TSK2.5. The feasible space for sample generation is defined by the parameter bounds established in Table 4. Except in the case of the free terms $b_{0, m}$, these bounds are the same as those imposed by Jacquin and Shamseldin (2006) for the calibration of the fuzzy models. In the case of the free terms $b_{0, m}$, whose values were not bounded during the calibration of the fuzzy models, the bounds shown in Table 4 are defined in such a manner that they are $50 \%$ wider than the range of $b_{0, m}$ values estimated by calibration of TSK 1.5 and TSK 2.5 for the test catchments. The performance of the fuzzy models is evaluated using the measures of goodness of fit indicated in Sect. 4.2. Probability distribution plots, produced using the software MCAT (Wagener and Kollat., 2007), are used for visually detecting sensitive parameters in the manner explained in Sect. 2.2.1.

\subsubsection{Application of the SVD method}

The SVD method is applied by splitting the model parameters in groups, with the purpose of clearly highlighting the importance of each model component in the performance of the fuzzy models. The groups considered are: 1) antecedent centres $c_{m}, 2$ ) antecedent spreads $\sigma_{m}, 3$ ) polynomial free terms $b_{0, m}$,4) polynomial coefficients $\left.b_{2, m}, 5\right)$ gamma distribution parameters $n_{m}$, and 6) gamma distribution parameters $(n K)_{m}$. In this case, the first-order effect of a group estimates to what extent the parameters in the group affect the model performance, excluding the effect of interactions with parameters outside the group. Similarly, the total effect sensitivity index of a group of parameters provides an estimation of the overall importance of the group in the performance of the fuzzy models, including interactions with parameters outside the group. The samples of model parameters and the sensitivity indices of the groups of parameters defined above are obtained with the sensitivity analysis software SIMLAB2.2 (European Union Joint Research Centre, 2004), using the Extended FAST sampling method (Saltelli et al., 1999). The bounds used for producing the samples of parameter sets are the same as those specified above for the case of the RSA method. The number of parameter sets in the sample is 9750 .

\section{Results}

\subsection{RSA results}

As examples of the application of the method, Figs. 1 and 2 show the results of RSA when applied to the fuzzy models TSK1.5 and TSK2.5, respectively, in the Sunkosi-1 catchment. In both figures, the model performance is evaluated using the efficiency criterion $R^{2}$. Only the plots corresponding to one fuzzy rule are shown, but similar ones are obtained for the remaining rules. From the analysis of Fig. 1, it can be concluded that the model efficiency $R^{2}$ of the fuzzy model TSK1.5 when applied in the Sunkosi-1 catchment is sensitive to changes in the parameters $c_{m}, \sigma_{m}$ and, particularly, $b_{0, m}$. The remaining parameters of TSK1.5 are either nonimportant for determining the efficiency $R^{2}$, or their influence arises from interactions that are not accounted for by the RSA method. Similarly, Fig. 2 shows that the model efficiency $R^{2}$ of the fuzzy model TSK2.5 is sensitive to the values taken by the parameters $\sigma_{m}, b_{0, m}$ and $b_{2, m}$. In this case, the RSA method does not reveal any sensitivity of the model efficiency $R^{2}$ with respect to the parameters $c_{m}, n_{m}$ and $n K_{m}$.

Table 5 presents a qualitative classification of the parameters of the fuzzy models, similar to that presented by Tang et al. (2007), based on visual analysis of plots such as those in Figs. 1 and 2. The RSA method was applied to the calibration and the verification data, finding similar sensitivity 

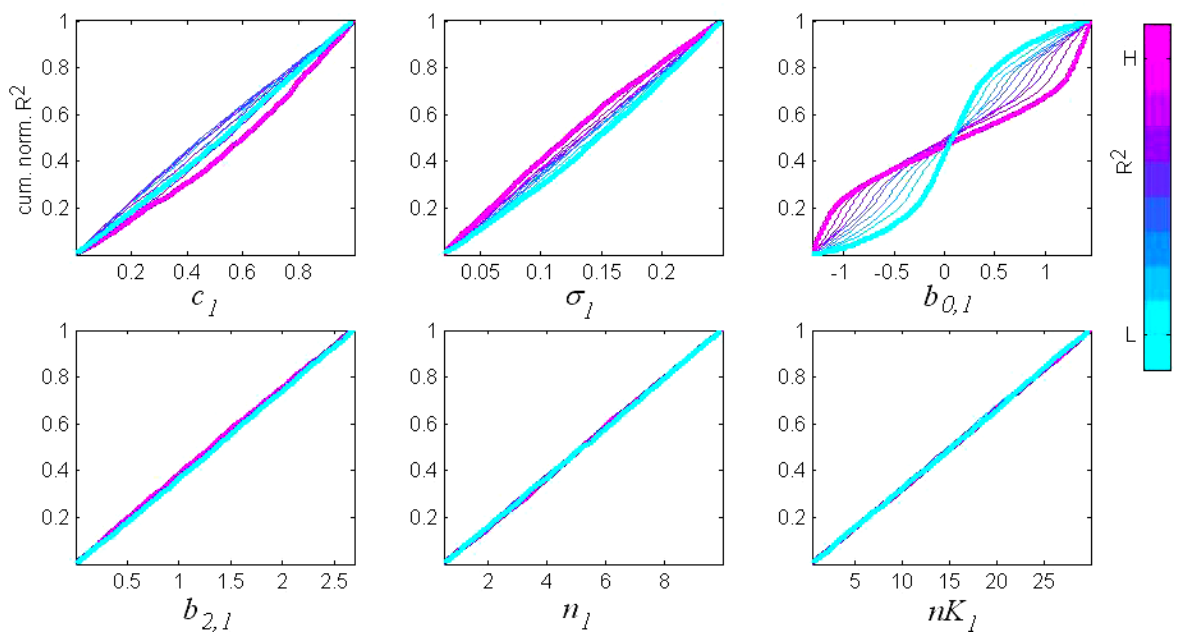

Fig. 1. Results of RSA method when applied to the fuzzy model TSK1.5 in the Sunkosi-1 catchment, using the efficiency criterion $R^{2}$ as a measure model performance.
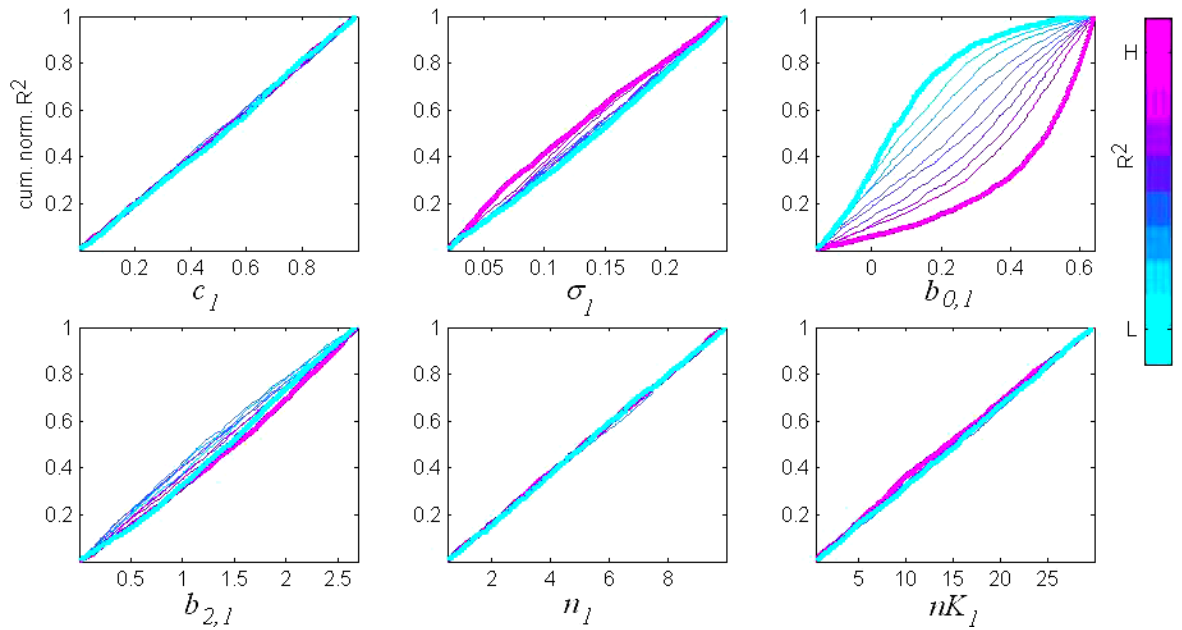

Fig. 2. Results of RSA method when applied to the fuzzy model TSK 2.5 in the Sunkosi- 1 catchment, using the efficiency criterion $R^{2}$ as a measure model performance.

patterns in both periods. It can be observed that parameter sensitivities of fuzzy models TSK1.5 and TSK2.5 differ, and that the sensitivity of the parameters of these fuzzy models depends on the type of catchment (seasonal or non-seasonal) where the models are applied. For example, the performance of TSK1.5 does not seem to be greatly affected by univariate changes in the parameters $b_{2, m}$ (see Fig. 1). In the case of the fuzzy model TSK2.5, however, the values of all three measures of model performance are sensitive to the parameters $b_{2, m}$, although only when TSK2.5 is applied in the seasonal catchments (see Fig. 2).

Table 5 also shows that the sensitivity of a parameter depends on the measure of model performance being considered. Comparison of the columns corresponding to $R^{2}$ and
REP reveals that these measures of model performance show sensitivity to the same type of parameters, which is not an unexpected result. Being based on the mean squared error, the model efficiency $R^{2}$ is very sensitive to the model errors in the high flow region, which is the zone of the discharge hydrograph that the measure REP is concerned with. Thus, it is not surprising that there is a strong correlation between both measures of model performance, with correlation coefficients in the Monte Carlo sample reaching -0.95 in some catchments. As a result, the parameter sensitivities of the measures $R^{2}$ and REP are similar. By contrast, parameter sensitivities of the performance measure REVF, which is more evenly sensitive to errors in the low and high flow ranges, are different from the other two. 
Table 5. Parameters of the fuzzy models deemed sensitive or very sensitive by the RSA method according to the measures of model performance $R^{2}$, REVF and REP.

\begin{tabular}{|c|c|c|c|c|c|c|c|}
\hline \multirow{2}{*}{$\begin{array}{l}\text { Catch- } \\
\text { ment } \\
\text { type }\end{array}$} & \multirow{2}{*}{$\begin{array}{l}\text { Para- } \\
\text { meter } \\
\text { group }\end{array}$} & \multicolumn{3}{|c|}{$\begin{array}{c}\text { Fuzzy model } \\
\text { TSK1.5 }\end{array}$} & \multicolumn{3}{|c|}{$\begin{array}{c}\text { Fuzzy model } \\
\text { TSK } 2.5\end{array}$} \\
\hline & & $R^{2}$ & REVF & REP & $R^{2}$ & REVF & REP \\
\hline \multirow[t]{6}{*}{ Seasonal } & $c_{m}$ & $S$ & S & $\mathrm{S}$ & - & - & - \\
\hline & $\sigma_{m}$ & $\mathrm{~S}$ & - & $\mathrm{S}$ & $\mathrm{S}$ & - & $\mathrm{S}$ \\
\hline & $b_{0, m}$ & VS & VS & VS & VS & VS & VS \\
\hline & $b_{2, m}$ & - & - & - & $\mathrm{S}$ & $S$ & $\mathrm{~S}$ \\
\hline & $n_{m}$ & - & - & - & - & - & - \\
\hline & $(n K)_{m}$ & - & - & - & - & - & - \\
\hline \multirow{6}{*}{$\begin{array}{l}\text { Non- } \\
\text {-seasonal }\end{array}$} & $c_{m}$ & $\mathrm{~S}$ & - & $\mathrm{S}$ & - & - & - \\
\hline & $\sigma_{m}$ & - & - & - & - & - & - \\
\hline & $b_{0, m}$ & VS & VS & VS & VS & VS & VS \\
\hline & $b_{2, m}$ & - & - & - & - & - & - \\
\hline & $n_{m}$ & - & - & - & - & - & - \\
\hline & $(n K)_{m}$ & - & - & - & - & - & - \\
\hline
\end{tabular}

In any case, a feature that is common to all models, catchments and measures of model performance is that the RSA method shows the polynomial free terms $b_{0, m}$ as the most sensitive parameters. In addition to this, the gamma distribution parameters $n_{m}$ and $(n K)_{m}$ are not revealed as sensitive in any fuzzy model or catchment.

\subsection{SVD results}

Tables 6 and 7 show the first-order effects for the fuzzy models TSK1.5 and TSK2.5, respectively. Similarly, Tables 8 and 9 show the total effects corresponding to TSK1.5 and TSK2.5, respectively. Sensitivity indices values are shaded according to the following criteria: Values greater than 0.3, seen as an indication of high sensitivity, are shaded in dark gray; values between 0.15 and 0.3 , interpreted as pointing out moderately sensitive parameters, are shaded in light gray; values between 0.02 and 0.15 , seen as indicating parameters with a modest (but non-negligible) sensitivity are not shaded; finally, values smaller than 0.02 , which are considered negligible, are highlighted in yellow. It seems important to point out that the sensitivity indices obtained for the calibration and the verification period are consistently close, which suggests that the results obtained in this analysis are independent on the period of data used for evaluation. The following discussion gives the conclusions obtained from the analysis of Tables 6 to 9, according to the criteria outlined in Sect. 2.2.2.

\subsubsection{First-order effects}

As explained in Sect. 2.2.2, the first-order effect of a group of parameters represents the sensitivity of the quantity $Y$ under examination to changes in the parameters of the group, without considering the effect of interactions with parame- ters outside the group. Except in the case where the interaction structure is such that its effects can be detected through RSA, the results of the RSA method provide similar information concerning the sensitivity of parameters. Therefore, it is not surprising that the analysis of the first-order effects in Tables 6 and 7 confirm the main results of the RSA method, presented in the previous section. In the first place, the highest first-order effects in Tables 6 and 7 correspond to the group of parameters $b_{0, m}$, which are the only parameters classified as very sensitive (VS) by the RSA method. In addition to this, the first-order effects of the groups of parameters classified as sensitive (S) by the RSA method are lower than in the previous case, although generally non-negligible. Finally, the first-order effects of those groups of parameters for which the RSA method did not reveal any sensitivity are negligible in all cases.

\subsubsection{Total effects}

Recalling the discussion in Sect. 2.2.2, the total effect of a group of parameters measures the sensitivity of the model response to the parameters in the group, including possible interactions with parameters in other groups. Accordingly, the total effects shown in Tables 8 and 9 are necessarily higher than the first-order effects in Tables 6 and 7, which exclude the effect of interactions outside the group. These interactions with other groups are revealed by great differences between the group's total effects and first-order effects. The following discussion analyses the sensitivity of each group of parameters according to their total effects and the existence of interactions between groups.

To start with, the total effects shown in Table 8 indicate that the free terms $b_{0, m}$ are the most influential for determining the performance of the fuzzy model TSK1.5, with respect to all three measures of model performance. It can also be seen that the sensitivity of the antecedent centres $c_{m}$ is also very high. In all catchments and measures of model performance, the differences between the total effects and the firstorder effects of both groups are large, which is not observed in the remaining groups. This situation indicates that, among all the groups of parameters, only the groups $c_{m}$ and $b_{0, m}$ are involved in strong interactions, and that this interactions occur mainly between them. Another feature shown in Table 8 is that the performance of the fuzzy model TSK1.5 can be moderately affected by the antecedent spreads $\sigma_{m}$. In particular, this group obtains total effects ranging between 0.16 and 0.28 for the measures of model performance $R^{2}$ and REP, with the highest total effects being observed in the seasonal catchments. In any case, this sensitivity is not observed in the case of the performance measure REVF, for which the total effects of this group are below 0.13 in all cases. Finally, analysis of Table 8 reveals that the remaining groups of parameters, namely the coefficients $b_{2, m}$ and the gamma distribution parameters $n_{m}$ and $(n K)_{m}$, have a very low importance for determining the performance of the fuzzy model 
Table 6. First-order effect sensitivity indices of the parameters of the fuzzy model TSK1.5. Dark gray shading indicates values greater than 0.3 and light gray shading indicates values between 0.15 and 0.3 . Values smaller than 0.02 are shaded in yellow.

\begin{tabular}{|c|c|c|c|c|c|c|c|}
\hline \multirow{2}{*}{$\begin{array}{l}\text { Catch- } \\
\text { ment }\end{array}$} & \multirow{2}{*}{$\begin{array}{l}\text { Para- } \\
\text { meter } \\
\text { group }\end{array}$} & \multicolumn{3}{|c|}{ Calibration } & \multicolumn{3}{|c|}{ Verification } \\
\hline & & $R^{2}$ & REVF & REP & $R^{2}$ & REVF & REP \\
\hline \multirow[t]{6}{*}{ Sunkosi-1 } & $c_{m}$ & 0.04 & 0.02 & 0.09 & 0.05 & 0.02 & 0.09 \\
\hline & $\sigma_{m}$ & 0.04 & 0.00 & 0.04 & 0.04 & 0.00 & 0.04 \\
\hline & $b_{0, m}$ & 0.58 & 0.59 & 0.40 & 0.56 & 0.56 & 0.38 \\
\hline & $b_{2, m}$ & 0.01 & 0.01 & 0.03 & 0.01 & 0.01 & 0.02 \\
\hline & $n_{m}$ & 0.01 & 0.00 & 0.01 & 0.01 & 0.01 & 0.01 \\
\hline & $(n K)_{m}$ & 0.01 & 0.00 & 0.01 & 0.01 & 0.01 & 0.01 \\
\hline \multirow[t]{6}{*}{ Yanbian } & $c_{m}$ & 0.06 & 0.02 & 0.08 & 0.06 & 0.02 & 0.08 \\
\hline & $\sigma_{m}$ & 0.03 & 0.01 & 0.06 & 0.03 & 0.01 & 0.06 \\
\hline & $b_{0, m}$ & 0.51 & 0.47 & 0.42 & 0.52 & 0.48 & 0.46 \\
\hline & $b_{2, m}$ & 0.01 & 0.00 & 0.01 & 0.01 & 0.00 & 0.01 \\
\hline & $n_{m}$ & 0.01 & 0.01 & 0.02 & 0.01 & 0.01 & 0.02 \\
\hline & $(n K)_{m}$ & 0.01 & 0.01 & 0.01 & 0.01 & 0.01 & 0.01 \\
\hline \multirow[t]{6}{*}{ Shiquan-3 } & $c_{m}$ & 0.07 & 0.02 & 0.09 & 0.07 & 0.02 & 0.10 \\
\hline & $\sigma_{m}$ & 0.02 & 0.01 & 0.02 & 0.02 & 0.01 & 0.03 \\
\hline & $b_{0, m}$ & 0.45 & 0.38 & 0.45 & 0.45 & 0.38 & 0.45 \\
\hline & $b_{2, m}$ & 0.01 & 0.01 & 0.01 & 0.01 & 0.01 & 0.01 \\
\hline & $n_{m}$ & 0.01 & 0.01 & 0.01 & 0.01 & 0.01 & 0.02 \\
\hline & $(n K)_{m}$ & 0.01 & 0.01 & 0.01 & 0.01 & 0.01 & 0.01 \\
\hline \multirow[t]{6}{*}{ Brosna } & $c_{m}$ & 0.08 & 0.02 & 0.08 & 0.08 & 0.02 & 0.08 \\
\hline & $\sigma_{m}$ & 0.04 & 0.01 & 0.06 & 0.05 & 0.01 & 0.06 \\
\hline & $b_{0, m}$ & 0.48 & 0.53 & 0.44 & 0.48 & 0.55 & 0.44 \\
\hline & $b_{2, m}$ & 0.01 & 0.01 & 0.02 & 0.01 & 0.01 & 0.02 \\
\hline & $n_{m}$ & 0.01 & 0.00 & 0.02 & 0.01 & 0.00 & 0.02 \\
\hline & $(n K)_{m}$ & 0.01 & 0.00 & 0.01 & 0.01 & 0.00 & 0.01 \\
\hline \multirow[t]{6}{*}{ Bird Creek } & $c_{m}$ & 0.06 & 0.02 & 0.09 & 0.06 & 0.02 & 0.08 \\
\hline & $\sigma_{m}$ & 0.02 & 0.01 & 0.03 & 0.02 & 0.01 & 0.02 \\
\hline & $b_{0, m}$ & 0.45 & 0.38 & 0.45 & 0.45 & 0.37 & 0.45 \\
\hline & $b_{2, m}$ & 0.01 & 0.01 & 0.01 & 0.01 & 0.01 & 0.01 \\
\hline & $n_{m}$ & 0.01 & 0.01 & 0.01 & 0.01 & 0.01 & 0.01 \\
\hline & $(n K)_{m}$ & 0.01 & 0.01 & 0.01 & 0.01 & 0.01 & 0.01 \\
\hline Wollombi & $c_{m}$ & 0.06 & 0.02 & 0.08 & 0.06 & 0.02 & 0.07 \\
\hline \multirow[t]{5}{*}{ Brook } & $\sigma_{m}$ & 0.02 & 0.01 & 0.03 & 0.02 & 0.01 & 0.03 \\
\hline & $b_{0, m}$ & 0.45 & 0.37 & 0.47 & 0.45 & 0.38 & 0.46 \\
\hline & $b_{2, m}$ & 0.01 & 0.01 & 0.01 & 0.01 & 0.01 & 0.01 \\
\hline & $n_{m}$ & 0.01 & 0.01 & 0.01 & 0.01 & 0.01 & 0.01 \\
\hline & $(n K)_{m}$ & 0.01 & 0.01 & 0.01 & 0.01 & 0.01 & 0.01 \\
\hline
\end{tabular}

TSK1.5, as the total effects of these groups are consistently small. More concretely, for all catchments and measures of model performance, the total effects of these groups do not exceed 0.14 .

The total effects shown in Table 9 indicate that the free terms $b_{0, m}$ are the parameters with the highest influence in the performance of TSK2.5, as indicated by all three measures of model performance and in all the catchments. Unlike the case of TSK1.5, the total effects of the antecedent centres $c_{m}$ are generally low. However, a high sensitivity is seen when the model TSK2.5 is applied in the seasonal catchments and the measure of model performance REP is used, in which case the total effects of the centres $c_{m}$ range between
Table 7. First-order effect sensitivity indices of the parameters of the fuzzy model TSK2.5. Dark gray shading indicates values greater than 0.3 and light gray shading indicates values between 0.15 and 0.3 . Values smaller than 0.02 are shaded in yellow.

\begin{tabular}{|c|c|c|c|c|c|c|c|}
\hline \multirow{2}{*}{$\begin{array}{l}\text { Catch- } \\
\text { ment }\end{array}$} & \multirow{2}{*}{$\begin{array}{l}\text { Para- } \\
\text { meter } \\
\text { group }\end{array}$} & \multicolumn{3}{|c|}{ Calibration } & \multicolumn{3}{|c|}{ Verification } \\
\hline & & $R^{2}$ & REVF & REP & $R^{2}$ & REVF & REP \\
\hline \multirow[t]{6}{*}{ Sunkosi-1 } & $c_{m}$ & 0.01 & 0.00 & 0.10 & 0.01 & 0.00 & 0.07 \\
\hline & $\sigma_{m}$ & 0.03 & 0.00 & 0.09 & 0.04 & 0.00 & 0.06 \\
\hline & $b_{0, m}$ & 0.59 & 0.62 & 0.22 & 0.57 & 0.63 & 0.27 \\
\hline & $b_{2, m}$ & 0.03 & 0.04 & 0.08 & 0.01 & 0.03 & 0.08 \\
\hline & $n_{m}$ & 0.00 & 0.00 & 0.01 & 0.00 & 0.00 & 0.01 \\
\hline & $(n K)_{m}$ & 0.00 & 0.00 & 0.02 & 0.00 & 0.00 & 0.01 \\
\hline \multirow[t]{6}{*}{ Yanbian } & $c_{m}$ & 0.01 & 0.00 & 0.09 & 0.01 & 0.00 & 0.09 \\
\hline & $\sigma_{m}$ & 0.02 & 0.00 & 0.10 & 0.02 & 0.00 & 0.10 \\
\hline & $b_{0, m}$ & 0.62 & 0.64 & 0.32 & 0.62 & 0.64 & 0.30 \\
\hline & $b_{2, m}$ & 0.01 & 0.02 & 0.07 & 0.01 & 0.02 & 0.06 \\
\hline & $n_{m}$ & 0.00 & 0.00 & 0.01 & 0.00 & 0.00 & 0.01 \\
\hline & $(n K)_{m}$ & 0.00 & 0.00 & 0.02 & 0.00 & 0.00 & 0.03 \\
\hline \multirow[t]{6}{*}{ Shiquan-3 } & $c_{m}$ & 0.00 & 0.00 & 0.01 & 0.00 & 0.00 & 0.01 \\
\hline & $\sigma_{m}$ & 0.02 & 0.00 & 0.01 & 0.02 & 0.00 & 0.02 \\
\hline & $b_{0, m}$ & 0.64 & 0.66 & 0.58 & 0.64 & 0.66 & 0.53 \\
\hline & $b_{2, m}$ & 0.00 & 0.00 & 0.01 & 0.00 & 0.00 & 0.01 \\
\hline & $n_{m}$ & 0.00 & 0.00 & 0.00 & 0.00 & 0.00 & 0.00 \\
\hline & $(n K)_{m}$ & 0.00 & 0.00 & 0.01 & 0.00 & 0.00 & 0.01 \\
\hline \multirow[t]{6}{*}{ Brosna } & $c_{m}$ & 0.00 & 0.00 & 0.06 & 0.01 & 0.00 & 0.08 \\
\hline & $\sigma_{m}$ & 0.03 & 0.00 & 0.13 & 0.03 & 0.00 & 0.14 \\
\hline & $b_{0, m}$ & 0.53 & 0.58 & 0.25 & 0.50 & 0.57 & 0.23 \\
\hline & $b_{2, m}$ & 0.13 & 0.11 & 0.13 & 0.13 & 0.12 & 0.11 \\
\hline & $n_{m}$ & 0.00 & 0.00 & 0.01 & 0.00 & 0.00 & 0.01 \\
\hline & $(n K)_{m}$ & 0.01 & 0.01 & 0.07 & 0.02 & 0.01 & 0.05 \\
\hline \multirow[t]{6}{*}{ Bird Creek } & $c_{m}$ & 0.00 & 0.00 & 0.01 & 0.00 & 0.00 & 0.01 \\
\hline & $\sigma_{m}$ & 0.01 & 0.00 & 0.01 & 0.01 & 0.00 & 0.01 \\
\hline & $b_{0, m}$ & 0.64 & 0.66 & 0.62 & 0.64 & 0.66 & 0.65 \\
\hline & $b_{2, m}$ & 0.00 & 0.00 & 0.00 & 0.00 & 0.00 & 0.00 \\
\hline & $n_{m}$ & 0.00 & 0.00 & 0.00 & 0.00 & 0.00 & 0.00 \\
\hline & $(n K)_{m}$ & 0.00 & 0.00 & 0.01 & 0.00 & 0.00 & 0.00 \\
\hline Wollombi & $c_{m}$ & 0.00 & 0.00 & 0.01 & 0.00 & 0.00 & 0.01 \\
\hline \multirow[t]{5}{*}{ Brook } & $\sigma_{m}$ & 0.01 & 0.00 & 0.01 & 0.01 & 0.00 & 0.01 \\
\hline & $b_{0, m}$ & 0.64 & 0.66 & 0.53 & 0.64 & 0.66 & 0.64 \\
\hline & $b_{2, m}$ & 0.00 & 0.00 & 0.02 & 0.00 & 0.00 & 0.02 \\
\hline & $n_{m}$ & 0.00 & 0.00 & 0.00 & 0.00 & 0.00 & 0.00 \\
\hline & $(n K)_{m}$ & 0.00 & 0.00 & 0.03 & 0.00 & 0.00 & 0.02 \\
\hline
\end{tabular}

0.31 and 0.48 . Similarly, the coefficients $b_{2, m}$ do not greatly affect the performance of TSK2.5, except for the high total effects seen in the seasonal catchments for the case of the measure of model performance REP. The last group having importance in determining the performance of TSK 2.5 is that of the antecedent spreads $\sigma_{m}$, for which the total effects range between 0.23 and 0.47 . Finally, Table 9 also reveals that the gamma distribution parameters $n_{m}$ and $(n K)_{m}$ are generally not influential for to the performance of the fuzzy model TSK2.5. In most cases, the total effects of these groups remain below 0.18 . The only exception is seen in the Brosna catchment, where the total effect of the parameters $(n K)_{m}$ in the measure of model performance REP reaches 0.29. 
Table 8. Total effect sensitivity indices of the parameters of the fuzzy model TSK1.5. Dark gray shading indicates values greater than 0.3 and light gray shading indicates values between 0.15 and 0.3 .

\begin{tabular}{|c|c|c|c|c|c|c|c|}
\hline \multirow{2}{*}{$\begin{array}{l}\text { Catch- } \\
\text { ment }\end{array}$} & \multirow{2}{*}{$\begin{array}{l}\text { Para- } \\
\text { meter } \\
\text { group }\end{array}$} & \multicolumn{3}{|c|}{ Calibration } & \multicolumn{3}{|c|}{ Verification } \\
\hline & & $R^{2}$ & REVF & REP & $R^{2}$ & REVF & REP \\
\hline \multirow[t]{6}{*}{ Sunkosi-1 } & $c_{m}$ & 0.51 & 0.32 & 0.54 & 0.55 & 0.35 & 0.53 \\
\hline & $\sigma_{m}$ & 0.17 & 0.08 & 0.20 & 0.17 & 0.08 & 0.23 \\
\hline & $b_{0, m}$ & 0.94 & 0.98 & 0.91 & 0.94 & 0.98 & 0.91 \\
\hline & $b_{2, m}$ & 0.09 & 0.05 & 0.17 & 0.09 & 0.06 & 0.16 \\
\hline & $n_{m}$ & 0.12 & 0.07 & 0.10 & 0.13 & 0.07 & 0.10 \\
\hline & $(n K)_{m}$ & 0.08 & 0.07 & 0.10 & 0.08 & 0.07 & 0.11 \\
\hline \multirow[t]{6}{*}{ Yanbian } & $c_{m}$ & 0.62 & 0.44 & 0.49 & 0.61 & 0.43 & 0.45 \\
\hline & $\sigma_{m}$ & 0.16 & 0.08 & 0.28 & 0.16 & 0.08 & 0.26 \\
\hline & $b_{0, m}$ & 0.93 & 0.98 & 0.87 & 0.93 & 0.98 & 0.88 \\
\hline & $b_{2, m}$ & 0.09 & 0.06 & 0.11 & 0.09 & 0.06 & 0.12 \\
\hline & $n_{m}$ & 0.13 & 0.08 & 0.12 & 0.13 & 0.08 & 0.11 \\
\hline & $(n K)_{m}$ & 0.08 & 0.08 & 0.09 & 0.08 & 0.08 & 0.09 \\
\hline \multirow[t]{6}{*}{ Shiquan-3 } & $c_{m}$ & 0.70 & 0.55 & 0.68 & 0.69 & 0.54 & 0.66 \\
\hline & $\sigma_{m}$ & 0.16 & 0.07 & 0.17 & 0.16 & 0.07 & 0.19 \\
\hline & $b_{0, m}$ & 0.93 & 0.98 & 0.91 & 0.93 & 0.98 & 0.89 \\
\hline & $b_{2, m}$ & 0.10 & 0.07 & 0.09 & 0.10 & 0.07 & 0.09 \\
\hline & $n_{m}$ & 0.14 & 0.09 & 0.12 & 0.13 & 0.09 & 0.13 \\
\hline & $(n K)_{m}$ & 0.09 & 0.08 & 0.08 & 0.09 & 0.08 & 0.09 \\
\hline \multirow[t]{6}{*}{ Brosna } & $c_{m}$ & 0.55 & 0.37 & 0.44 & 0.54 & 0.34 & 0.45 \\
\hline & $\sigma_{m}$ & 0.21 & 0.12 & 0.27 & 0.23 & 0.13 & 0.27 \\
\hline & $b_{0, m}$ & 0.89 & 0.98 & 0.87 & 0.88 & 0.97 & 0.88 \\
\hline & $b_{2, m}$ & 0.12 & 0.06 & 0.14 & 0.13 & 0.05 & 0.14 \\
\hline & $n_{m}$ & 0.12 & 0.06 & 0.11 & 0.12 & 0.06 & 0.12 \\
\hline & $(n K)_{m}$ & 0.09 & 0.07 & 0.11 & 0.09 & 0.07 & 0.11 \\
\hline Bird & $c_{m}$ & 0.69 & 0.55 & 0.67 & 0.70 & 0.55 & 0.69 \\
\hline \multirow[t]{5}{*}{ Creek } & $\sigma_{m}$ & 0.16 & 0.07 & 0.17 & 0.16 & 0.07 & 0.16 \\
\hline & $b_{0, m}$ & 0.94 & 0.98 & 0.90 & 0.94 & 0.98 & 0.91 \\
\hline & $b_{2, m}$ & 0.10 & 0.07 & 0.09 & 0.10 & 0.07 & 0.09 \\
\hline & $n_{m}$ & 0.13 & 0.09 & 0.12 & 0.14 & 0.09 & 0.12 \\
\hline & $(n K)_{m}$ & 0.09 & 0.08 & 0.08 & 0.09 & 0.08 & 0.08 \\
\hline Wollombi & $c_{m}$ & 0.69 & 0.55 & 0.63 & 0.69 & 0.55 & 0.64 \\
\hline \multirow[t]{5}{*}{ Brook } & $\sigma_{m}$ & 0.16 & 0.07 & 0.16 & 0.16 & 0.07 & 0.17 \\
\hline & $b_{0, m}$ & 0.94 & 0.98 & 0.91 & 0.94 & 0.98 & 0.91 \\
\hline & $b_{2, m}$ & 0.10 & 0.07 & 0.09 & 0.10 & 0.07 & 0.10 \\
\hline & $n_{m}$ & 0.13 & 0.09 & 0.12 & 0.13 & 0.09 & 0.12 \\
\hline & $(n K)_{m}$ & 0.09 & 0.08 & 0.09 & 0.09 & 0.08 & 0.10 \\
\hline
\end{tabular}

\section{Conclusions}

This study has analysed the sensitivity of the parameters of the Takagi-Sugeno-Kang rainfall-runoff fuzzy models proposed by Jacquin and Shamseldin (2006). These models can be classified in two model types, each consisting of five model structures of increasing complexity. The fuzzy models TSK 1.5 and TSK2.5 are the most complex within types 1 and 2 , respectively, and they include all the model components found in the simpler fuzzy models of the corresponding group. Two global sensitivity analysis methods were applied, namely the RSA and SVD methods. In general, the
Table 9. Total effect sensitivity indices of the parameters of the fuzzy model TSK2.5. Dark gray shading indicates values greater than 0.3 and light gray shading indicates values between 0.15 and 0.3 .

\begin{tabular}{|c|c|c|c|c|c|c|c|}
\hline \multirow{2}{*}{$\begin{array}{l}\text { Catch- } \\
\text { ment }\end{array}$} & \multirow{2}{*}{$\begin{array}{l}\text { Para- } \\
\text { meter } \\
\text { group }\end{array}$} & \multicolumn{3}{|c|}{ Calibration } & \multicolumn{3}{|c|}{ Verification } \\
\hline & & $R^{2}$ & REVF & REP & $R^{2}$ & REVF & REP \\
\hline \multirow[t]{6}{*}{ Sunkosi-1 } & $c_{m}$ & 0.07 & 0.03 & 0.42 & 0.10 & 0.03 & 0.38 \\
\hline & $\sigma_{m}$ & 0.29 & 0.23 & 0.37 & 0.29 & 0.23 & 0.33 \\
\hline & $b_{0, m}$ & 0.95 & 0.95 & 0.84 & 0.95 & 0.95 & 0.84 \\
\hline & $b_{2, m}$ & 0.10 & 0.08 & 0.59 & 0.09 & 0.07 & 0.48 \\
\hline & $n_{m}$ & 0.03 & 0.02 & 0.10 & 0.03 & 0.02 & 0.08 \\
\hline & $(n K)_{m}$ & 0.04 & 0.03 & 0.13 & 0.04 & 0.03 & 0.11 \\
\hline \multirow[t]{6}{*}{ Yanbian } & $c_{m}$ & 0.04 & 0.03 & 0.44 & 0.05 & 0.03 & 0.48 \\
\hline & $\sigma_{m}$ & 0.28 & 0.23 & 0.41 & 0.27 & 0.23 & 0.39 \\
\hline & $b_{0, m}$ & 0.96 & 0.98 & 0.84 & 0.96 & 0.97 & 0.84 \\
\hline & $b_{2, m}$ & 0.06 & 0.05 & 0.43 & 0.06 & 0.05 & 0.46 \\
\hline & $n_{m}$ & 0.03 & 0.02 & 0.10 & 0.03 & 0.02 & 0.12 \\
\hline & $(n K)_{m}$ & 0.03 & 0.03 & 0.18 & 0.03 & 0.03 & 0.18 \\
\hline \multirow[t]{6}{*}{ Shiquan-3 } & $c_{m}$ & 0.03 & 0.03 & 0.12 & 0.03 & 0.03 & 0.18 \\
\hline & $\sigma_{m}$ & 0.26 & 0.23 & 0.24 & 0.26 & 0.23 & 0.25 \\
\hline & $b_{0, m}$ & 0.98 & 0.99 & 0.97 & 0.98 & 0.99 & 0.96 \\
\hline & $b_{2, m}$ & 0.03 & 0.03 & 0.05 & 0.04 & 0.03 & 0.06 \\
\hline & $n_{m}$ & 0.03 & 0.02 & 0.03 & 0.03 & 0.02 & 0.04 \\
\hline & $(n K)_{m}$ & 0.03 & 0.02 & 0.04 & 0.03 & 0.02 & 0.06 \\
\hline \multirow[t]{6}{*}{ Brosna } & $c_{m}$ & 0.05 & 0.03 & 0.31 & 0.07 & 0.03 & 0.34 \\
\hline & $\sigma_{m}$ & 0.27 & 0.23 & 0.43 & 0.28 & 0.23 & 0.47 \\
\hline & $b_{0, m}$ & 0.86 & 0.89 & 0.76 & 0.85 & 0.86 & 0.78 \\
\hline & $b_{2, m}$ & 0.23 & 0.16 & 0.52 & 0.26 & 0.19 & 0.54 \\
\hline & $n_{m}$ & 0.03 & 0.02 & 0.08 & 0.03 & 0.02 & 0.11 \\
\hline & $(n K)_{m}$ & 0.06 & 0.04 & 0.29 & 0.07 & 0.04 & 0.28 \\
\hline \multirow[t]{6}{*}{ Bird Creek } & $c_{m}$ & 0.03 & 0.03 & 0.08 & 0.03 & 0.03 & 0.06 \\
\hline & $\sigma_{m}$ & 0.26 & 0.23 & 0.24 & 0.26 & 0.24 & 0.23 \\
\hline & $b_{0, m}$ & 0.98 & 0.99 & 0.98 & 0.98 & 0.99 & 0.98 \\
\hline & $b_{2, m}$ & 0.03 & 0.03 & 0.04 & 0.03 & 0.03 & 0.04 \\
\hline & $n_{m}$ & 0.03 & 0.02 & 0.03 & 0.03 & 0.02 & 0.03 \\
\hline & $(n K)_{m}$ & 0.03 & 0.02 & 0.04 & 0.03 & 0.02 & 0.04 \\
\hline Wollombi & $c_{m}$ & 0.03 & 0.03 & 0.14 & 0.03 & 0.03 & 0.06 \\
\hline \multirow[t]{5}{*}{ Brook } & $\sigma_{m}$ & 0.26 & 0.23 & 0.25 & 0.26 & 0.23 & 0.24 \\
\hline & $b_{0, m}$ & 0.98 & 0.99 & 0.93 & 0.97 & 0.99 & 0.95 \\
\hline & $b_{2, m}$ & 0.04 & 0.03 & 0.10 & 0.04 & 0.03 & 0.07 \\
\hline & $n_{m}$ & 0.03 & 0.02 & 0.05 & 0.03 & 0.02 & 0.05 \\
\hline & $(n K)_{m}$ & 0.03 & 0.02 & 0.11 & 0.03 & 0.03 & 0.08 \\
\hline
\end{tabular}

RSA method has the disadvantage of not being able to detect sensitivities arising from parameter interactions. By contrast, the SVD method is suitable for analysing models where the model response surface is expected to be affected by interactions at a local scale and/or local optima, such as the case of the rainfall-runoff fuzzy models of Jacquin and Shamseldin (2006).

Overall, the results of this study reveal that parameter sensitivities of fuzzy models TSK1.5 and TSK2.5 depend on the type of non-linear effects (i.e. seasonality or intrinsic nonlinearity) that dominates the catchment's rainfall-runoff relationship. It was also observed that, for a given catchment, 
parameter sensitivities vary according to the statistic chosen for evaluating model performance. For example, the total effects of the antecedent centres $c_{m}$ in the performance of TSK2.5 are generally low, but the statistic REP (reflecting the relative error to the peak) was found to be very sensitivity to these parameters in the case of the seasonal catchments. These results are in agreement with previous research, showing that the sensitivity of the parameters of a rainfall-runoff model is dependent on the catchment's hydroclimatic characteristics and on the measure of model performance (Tang et al., 2007; van Werkhoven et al., 2008). However, broad generalizations on parameter sensitivities of the fuzzy models TSK1.5 and TSK2.5 can still be attempted, with the purpose of facilitating the calibration process by identifying the parameters with the highest influence in the model's goodness of fit, and those which can be fixed without important loss of accuracy in the discharge estimates.

In the case of the fuzzy model TSK1.5, it was found that the performance of the model is quite sensitive to the antecedent centres $c_{m}$, although most of this influence is due to interactions with the parameters $b_{0, m}$. It was also observed that the antecedent spreads $\sigma_{m}$ have a moderate importance in determining the model performance of TSK1.5. Similarly, it was observed that the antecedent parameters $c_{m}$ and $\sigma_{m}$ generally do not have a high influence in the performance of TSK2.5. These situations imply that the actual definition of the antecedent fuzzy sets is not, on its own, a determinant factor for the goodness of fit of the fuzzy models TSK1.5 and TSK2.5. It would be possible to fix the antecedent parameters prior to the calibration of the fuzzy models without an important deterioration of model performance, provided that the values of the remaining parameters are conveniently adjusted.

It was also observed that, in general, the coefficients $b_{2, m}$ do not greatly affect the performance of TSK1.5 and TSK2.5. By contrast, the free terms $b_{0, m}$ were identified as the parameters with the highest influence in the performance of TSK1.5 and TSK2.5. Moreover, these parameters exhibit quite high (and also the highest) first-order effects in all cases, modifying the model performance independently of interactions with parameters in other groups. As pointed out by Saltelli et al. (2004), the identification of appropriate values for parameters with a high first-order effect should be a priority during the process of model calibration. Nevertheless, Jacquin and Shamseldin (2006) showed that removing the parameters $b_{0, m}$, by moving from the fuzzy models TSKx.3 and TSKx.5 to the simpler TSKx.2 and TSKx.4, respectively, does not have a significant impact in the performance of the optimised rainfall-runoff fuzzy model. This situation indicates that finding the "true" values of the free terms $b_{0, m}$ does not necessarily improve the goodness of fit, as long as these parameters are all assigned zero values.

This apparent contradiction between the findings of Jacquin and Shamseldin (2006) and the results of the sensitivity analysis presented in this study can be explained af- ter a more careful consideration of the facts. First, the large total and first-order effects of the parameters $b_{0, m}$ indicate that allowing a free variation of these parameters across their feasible range does produce important changes in the goodness of fit of the fuzzy models TSK1.5 and TSK2.5. In fact, assigning very inappropriate values to these parameters may result in an important deterioration of model performance; for example, assigning highly negative values to the parameters $b_{0, m}$ in all of the rules would result in highly negative discharge estimates in cases where the most recent rainfall segment is null. However, it is still possible that a relatively good (and nearly optimal) model response can be obtained by fixing the values of the parameters $b_{0, m}$ as zero and calibrating the remaining model parameters accordingly.

Finally, the results of this study indicate that the gamma distribution parameters $n_{m}$ and $(n K)_{m}$ are almost unimportant in determining the goodness of fit of the fuzzy models TSK1.5 and TSK2.5. These results are in agreement with the findings of Jacquin and Shamseldin (2006), in the sense that allowing a different pulse response for each rule consequent (i.e. moving from the fuzzy models TSKx.2 and TSKx.3 to TSKx.4 and TSKx.5, respectively) does not necessarily improve the performance of the optimised fuzzy model. In order to reduce the dimensionality of the optimisation problem associated with the calibration of the model, these parameters could be excluded from the search of the behavioural regions of the parameter space, by assigning to them fixed values within their feasible ranges. For example, the values of the parameters $n_{m}$ and $(n K)_{m}$ of all the fuzzy rules could be given the same values as those of the auxiliary SLM. As seen in Sect. 3.2, this would be equivalent to abandoning the models TSK1.5 and TSK2.5 in favour of the more parsimonious TSK1.3 and TSK2.3, respectively.

Further work could explore the application of the GSA methods applied in this paper to other hydrological models based on soft computing methods. For example, it would be convenient to perform sensitivity analysis of other fuzzy model structures. Similarly, it would also be interesting to use this methods method for investigating the relative importance of the parameters of typical neural network based rainfall-runoff models. The application of the method would allow identifying those parameters whose values can be fixed without important deterioration in model performance and those parameters whose appropriate calibration is most important.

Acknowledgements. This research was supported by FONDECYT, Research Grant 11070130. We would also like to express our gratitude to Kieran M. O'Connor from the National University of Ireland, Galway, for providing the data used in this study. Finally, we would like convey our appreciation to the editor Erwin Zehe and the anonymous referees for their constructive criticisms, which have helped us to improve the quality of the manuscript.

Edited by: E. Zehe 


\section{References}

Bárdossy, A. Bronstert, A., and Merz, B.: 1-, 2- and 3-dimensional modelling of water movement in the unsaturated soil matrix using a fuzzy approach, Adv. Water Resour., 18(4), 237-251, 1995.

Bárdossy, A. and Disse, M.: Fuzzy Rule-Based Models for Infiltration, Water Resour. Res., 29(2), 373-382, 1993.

Bárdossy, A., Mascellani, G., and Franchini, M.: Fuzzy unit hydrograph, Water Resour. Res., 42(2), W02401, doi:10.1029/2004WR003751, 2006.

Beven, K. J.: Rainfall-Runoff Modelling: The Primer, John Wiley \& Sons, Chichester, 360 pp., 2001.

Castaings, W., Dartus, D., Honnorat, M., Le Dimet, F. X., Loukili, Y., and Monnier, J.: Automatic differentiation: a tool for variational data assimilation and adjoint sensitivity analysis for flood modelling, in: Automatic Differentiation: Applications, Theory, and Tools, edited by: Bücker, H. M., Corliss, G., Hovland, P., Naumann, U., and Norris, B., Springer, Chicago, 249-262, 2005.

Chan, K., Tarantola, S., Saltelli, A., and Sobol, I. M.: Variancebased methods, in: Sensitivity Analysis, edited by: Saltelli, A., Chan, K., and Scott, E. M., John Wiley \& Sons, Chichester, 167197, 2000.

Cukier, R. I., Fortuin, C. M., Shuler, K. E., Petschek, A. G., and Schaibly, J. H.: A Study of the Sensitivity of Coupled Reaction Systems to Uncrtainties in Rate Coefficients: I Theory, J. Chem. Phys., 59(8), 3873-3878, 1973.

Cukier, R. I., Levine, H. B., and Shuler, K. E.: Nonlinear sensitivity analysis of multiparameter model systems, J. Comput. Phys., 26, $1-42,1978$

Demicco, R. and Klir, G.: Fuzzy Logic in Geology, Academic Press, Amsterdam, 347 pp., 2004.

Dou, X., Wouldt, W., and Bogardi, I.: Fuzzy rule-based approach to describe solute transport in the unsaturated zone, J. Hydrol., 220, 74-85, 1999.

European Union Joint Research Centre: SIMLAB: Simulation Environment for Uncertainty and Sensitivity Analysis (version 2.2), Applied Statistics Sector, Institute for Systems, Informatics and Safety, European Union Joint Research Centre, Ispra, Italy, 2004.

Fieberg, J. and Jenkings, K. J.: Assessing uncertainty in ecological systems using global sensitivity analyses: a case example of simulated wolf reintroduction effects on elk, Ecol. Model., 187, 259-280, 2005.

Francos, A., Elorzab, F. J., Bouraouia, F., Bidoglioa, G., and Galbiatia, L.: Sensitivity analysis of distributed environmental simulation models: understanding the model behaviour in hydrological studies at the catchment scale, Reliab. Eng. Syst. Safe., 205-218, 2003.

Gupta, V. K. and Sorooshian, S.: The automatic calibration of conceptual catchment models using derivative-based optimization algorithms, Water Resour. Res., 21(4), 473-485, 1985.

Homma, T. and Saltelli, A.: Importance measures in global sensitivity analysis of model output, Reliab. Eng. Syst. Safe, 52, 1-17, 1996.

Hornberger, G. M. and Spear, R. C.: An approach to the preliminary analysis of environmental systems, J. Environ. Manage., 12, 718, 1981.

Hundecha, Y. and Bárdossy, A.: Modeling of the effect of land use changes on the runoff generation of a river basin through parameter regionalization of a watershed model, J. Hydrol., 292, 281-295, 2004
Hundecha, Y., Bárdossy, A., and Theisen, H.-W.: Development of a fuzzy logic-based rainfall-runoff model, Hydrolog. Sci. J., 46(3), 363-376, 2001.

Jacquin, A. P. and Shamseldin, A. Y.: Development of rainfallrunoff models using Takagi-Sugeno-Kang fuzzy inference systems, J. Hydrol., 329, 154-173, 2006.

Jacquin, A. P. and Shamseldin, A. Y.: Development of a possibilistic method for the evaluation of predictive uncertainty in rainfall-runoff modelling, Water Resour. Res., 43(4), W04425, doi:10.1029/2006WR005072, 2007.

Kanso, A., Chebboa, G., and Tassina, B.: Application of MCMCGlobal sensitivity analysis method for model calibration to urban runoff quality model, in: Sensitivity Analysis of Model Output, edited by: Hanson, K. M. and Hemez, F. M., Los Alamos National Laboratory, 17-26, available at: http://library.lanl.gov, 2005.

McIntyre, N. R., Wagener, T., Wheater, H., and Chapra, S. C.: Riskbased modelling of surface water quality: a case study of the Charles River, Massachussetts, J. Hydrol., 274, 225-247, 2003.

Mein, R. G. and [yellow], B. M.: Sensitivity of optimized parameters in watershed models, Water Resour. Res., 14(2), 299-303, 1978.

Mertens, J., Madsen, H., Kristensen, M., Jacques, D., and Feyen, J.: Sensitivity of soil parameters in saturated zone modelling and the relation between effective, laboratory and in situ estimates, Hydrol. Process., 19(8), 1611-1633, doi:10.1002/hyp.5591, 2005.

Morris, M. D.: Factorial sampling plans for preliminary computational experiments, Technometrics, 33(2), 161-074, 1991.

Nandakumar, N. and Mein, R. G.: Uncertainty in rainfall-runoff model simulations and the implications for predicting the hydrologic effects of land-use change, J. Hydrol., 192, 211-232, 1997.

Nash, J. E.: The form of the instantaneous unit hydrograph, IASH Publication, 45(3), 114-118, 1957.

Nash, J. E. and Foley, J. J.: Linear models of rainfall-runoff systems, in: Rainfall-runoff relationships, Proceedings of the International Symposium on Rainfall-Runoff Modeling, Mississippi State University, USA, May 1981, 51-66, 1982.

Nash, J. E. and Sutcliffe, J. V.: River flow forecasting through conceptual models, Part I - A discussion of principles, J. Hydrol., 10, 282-290, 1970.

O'Connor, K. M.: River flow forecasting, in: River Basin Modelling for Flood Risk Mitigation, edited by: Knight, D. W. and Shamseldin A. Y., Taylor \& Francis, London, 197-213, 2005.

Özelkan, E. C. and Duckstein, L.: Fuzzy conceptual rainfall-runoff models, J. Hydrol., 253, 41-68, 2001.

Özelkan, E. C., Galambosi, A., Duckstein, L., and Bárdossy, A. A multi-objective fuzzy classification of large scale atmospheric circulation patterns for precipitation modelling, Appl. Math. Comput., 91, 127-142, 1998.

Pappenberger, F., Beven, K. J., Ratto, M., and Matgen, P.: Multimethod global sensitivity analysis of flood inundation models, Adv. Water Resour., 31(1), 1-14, 2008.

Pongracz, R., Bartholy, J., and Bogardi, I. Fuzzy rule-based prediction of monthly precipitation, Phys. Chem. Earth Pt. B, 26(9), 663-667, 2001.

Ratto, M., Young, P. C., Romanowicz, R., Pappenberger, F., Saltelli, A., and Pagano, A.: Uncertainty, sensitivity analysis and the role of data based mechanistic modeling in hydrology, Hydrol. Earth Syst. Sci., 11, 1249-1266, 2007, 
http://www.hydrol-earth-syst-sci.net/11/1249/2007/.

Saltelli, A., Ratto, M., Andres, T., Campolongo, F., Cariboni, J., Gatelli, D., Saisana, M., and Tarantola, S.: Global Sensitivity Analysis: The Primer, John Wiley \& Sons, Chichester, 292 pp., 2008.

Saltelli, A., Tarantola, S., and Campolongo, F.: Sensitivity analysis as an ingredient of modelling, Stat. Sci., 15(4), 377-395, 2000.

Saltelli, A., Tarantola, S., Campolongo, F., and Ratto, M.: Sensitivity analysis in practice: A guide to assessing scientific models, John Wiley \& Sons, Chichester, 219 pp., 2004.

Saltelli, A., Tarantola, S., and Chan, K.: A quantitative, model independent method for global sensitivity analysis of model output, Technometrics, 41(1), 39-56, 1999.

Seibert, J.: Regionalization of parameter of a conceptual rainfallrunoff model, Agr. Forest Meteorol., 98-99, 279-293, 1999.

Sobol, I. M.: Sensitivity analysis for non-linear mathematical models, Mathematical Modelling and Computational Experiments, 1(4), 407-414, 1993.

Sorooshian, S. and Gupta, V. K.: Model calibration, in: Conceptual Models of Watershed Hydrology, edited by: Singh, V. P., Water Resources Publications, Colorado, 23-67, 1995.

Spear, R. C. and Hornberger, G. M.: Eutrophication in Peel Inlet II: Identification of critical uncertainties via generalised sensitivity analysis, Water Resour. Res., 14, 43-49, 1980.

Sugeno, M. and Kang, G. T.: Structure identification of fuzzy model, Fuzzy Set. Syst., 28, 15-33, 1988.

Takagi, T. and Sugeno, M.: Fuzzy identification of systems and its application to modeling and control, IEEE T. Syst. Man Cyb., SMC-15(1), 116-132, 1985.

Tang, Y., Reed, P., Wagener, T., and van Werkhoven, K.: Comparing sensitivity analysis methods to advance lumped watershed model identification and evaluation, Hydrol. Earth Syst. Sci., 11, 793817, 2007, http://www.hydrol-earth-syst-sci.net/11/793/2007/.

Vernieuwe, H., Georgieva, O., De Baets, B., Pauwels, V. R. N., Verhoest, N. E. C., and De Troch, F. P.: Comparison of datadriven Takagi-Sugeno models of rainfall-discharge dynamics, J. Hydrol., 302, 173-186, 2005.

Wagener, T., Boyle, D. P., Lees, M. J., Wheater, H. S., Gupta, H. V., and Sorooshian, S.: A framework for development and application of hydrological models, Hydrol. Earth Syst. Sci., 5, 13-26, 2001, http://www.hydrol-earth-syst-sci.net/5/13/2001/.
Wagener, T. and Kollat, J.: Numerical and visual evaluation of hydrological and environmental models using the Monte Carlo analysis toolbox, Environ. Modell. Softw., 22(7), 1021-1033, 2007.

Wagener, T., Wheater, H. S., and Gupta, H. V.: Identification and evaluation of watershed models, in: Calibration of Watershed Models, edited by: Duan, Q., Gupta, H. V., Sorooshian, S., Rousseau, A. N., and Turcotte, R., American Geophysical Union, Washington, 29-47, 2002.

Wang, X., Frankenberger, J. R., and Kladivko, E. J.: Uncertainties in DRAINMOD predictions of subsurface drain flow for and Indiana silt loam using the GLUE methodology, Hydrol. Process., 20(14), 3069-3084, doi:10.1002/hyp.6080, 2006.

van Werkhoven, K., Wagener, T., Reed, P., and Tang, Y.: Characterization of watershed model behavior across a hydroclimatic gradient, Water Resour. Res., 44, W01429, doi:10.1029/2007WR006271, 2008.

Xiong, L. and O'Connor, K. M.: Analysis of the response surface of the objective function by the optimum parameter curve: How good can the optimum parameter values be?, J. Hydrol., 234, 187-207, 2000.

Yu, P.-S., and Yang, T. C.: Fuzzy multi-objective function for rainfall-runoff model calibration, J. Hydrol., 238, 1-14, 2000.

Zadeh, L. A.: Fuzzy Sets, Inform. Control, 8(3), 338-353, 1965.

Zehe, E., Becker, R., Bárdossy, A. and Plate, E. Uncertainty of simulated catchment runoff response in the presence of threshold processes: Role of initial soil moisture and precipitation, J. Hydrol., 315, 183-202, 2005.

Zehe, E. and Blöschl, G.: Predictability of hydrologic response at the plot and catchment scales: The role of initial conditions, Water Resour. Res., 40(10), W10202, doi:10.1029/2003WR002869, 2004.

Zehe, E., Singh, A. K., and Bárdossy, A.: Modelling of monsoon rainfall for a mesoscale catchment in North-West India I: assessment of objective circulation patterns, Hydrol. Earth Syst. Sci., 10, 797-806, 2006, http://www.hydrol-earth-syst-sci.net/10/797/2006/. 